\title{
Corrosion Behavior and Mechanical Properties of Mg-Based Alloys by Rapid Solidification Technology of Twin Roll Casting
}

\author{
Haijian Wang ${ }^{1, a}$, Zhipu Pei ${ }^{1, b}$ and Dongying $\mathrm{Ju}^{2, \mathrm{c}}{ }^{*}$ \\ ${ }^{1}$ Department of Material Science and Engineering, Saitama Institute of Technology Fusaiji1690, \\ Fukaya, Saitama 369-0293, Japan \\ 2Department of Material Science and Engineering, University of Science and Technology Liaoning, \\ No.185 Qianshan Mid-Road, Anshan, Liaoning, 114051, China
}

ae7002qox@sit.ac.jp, bpeizhipu@gmail.com, cdyju@sit.ac.jp

\begin{abstract}
Keywords: Mg-Based alloy; quasi-amorphous; corrosion resistance; mechanical p
\end{abstract}
Abstract. Mg-based alloys were prepared by rapid solidification of twin ro 1 casting $\mathrm{RC}$ ) hich shows that the Mg-RE alloy expressed the quasi-amorphous phased and $f^{f}$ ne crys glline se dualphase material. Corrosion behavior of $\mathrm{Mg}$-Based alloy in $3.5 \% \mathrm{NaCl}$ or an iter 4 immersion and mechanical properties were investigated. The result show that 1 e $M g-$ alloy sip exhibited good corrosion resistance and higher ultimate tensile strength and gation co ing to the AZ31 alloy strips. The elongation of Mg-RE alloy strip is also high th the 791 and $Z$ A 61 under powder metallurgy processing. These indicate that Mg-RE alloy auced $\mathrm{u}$ ur method has a better ductility. This may due to the special microstructure of th $\mathrm{Mg}-\mathrm{RE}$ alloy fo, 1 s, i.e., quasi-amorphous phase plus fine crystalline phase dual phase state.

\section{Introduction}

The term lightweight has been proposed form and it is still a hot topic in modern society, magnesium and its alloys as lightweight a crial, e well accepted for many applications in automobile and aerospace industries. $v e r$, the pplications of $\mathrm{Mg}$ alloys are very limited because of the restricted plasticity of $\mathrm{Mg}$ owin to the $\mathrm{h}$ agonal closed-packed crystal structure which possesses few slip systems) and the or form a protective oxide film) comparing with other metal $[1,2]$. adopting nanocrystalline or quasicrystalline [3] phases it provides an efficient way pprove th ctility and corrosion resistance of the $\mathrm{Mg}$ alloys and is

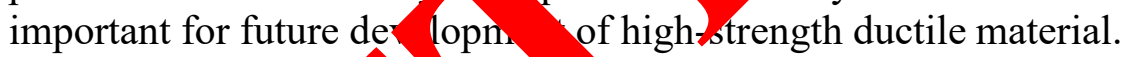

Twin-roll strip ang proco combines casting and hot rolling into a single step, having an advantage of on step rocessing if flat rolled products [4]. Besides being such a cost-effective process, twin $\pi$ tri casti $g$ also has beneficial effects on microstructure such as reducing segregation and gi size wi a consequent improvement of mechanical properties and corrosion resistanc $-\mathrm{J}$ In this $\mathrm{rr}^{\mathrm{r}}$, we focused on developing a new kind of Mg-based alloy with proper mech cal p formanc and good corrosion resistance. Considering its application, we proposed a cost-con od to produce the new material in sheet-form. It is considered as an efficient mass-produ on technique.

\section{Experimental}

The ingots of $\mathrm{Mg}$-RE alloy were prepared by induction melting the mixture of pure $\mathrm{Mg}, \mathrm{Al}$ and $\mathrm{RE}$ (for Mg-RE alloy) in an induction furnace under the protection of high-purity argon. Chemical compositions of the ingots were measured by X-ray Fluorescence spectrometry and the results are listed in Table 1. Twin roll casting experiments were carried out under casting conditions of casting speed $30 \mathrm{~m} / \mathrm{min}$ and pouring temperature $953 \mathrm{~K}$. Initial roll gap was set as $0 \mathrm{~mm}$. An oil tank was set directly down to the rolls to avoid further grain growth as the as-cast strip was dipped into the oil tank as soon as it exits from the rolls. 
Table 1. Composition of the Mg-RE alloy

\begin{tabular}{cccccccc}
\hline Elements & $\mathrm{Mg}$ & $\mathrm{Al}$ & $\mathrm{Si}$ & $\mathrm{Mn}$ & $\mathrm{Zn}$ & $\mathrm{La}$ & $\mathrm{Ce}$ \\
\hline $\mathrm{at} \%$ & 94.6 & 3.99 & 0.107 & 0.12 & 0.04358 & 0.464 & 0.66 \\
$\mathrm{wt} \%$ & 89.2427 & 4.1779 & 0.1169 & 0.2550 & 0.1106 & 2.5007 & 3.5963 \\
\hline
\end{tabular}

Specimens alloy with a dimension of $14 \mathrm{~mm} \times 14 \mathrm{~mm} \times 1 \mathrm{~mm}$ were prepared for scanning electron microscope (SEM) and electron probe micro-analysis (EPMA) were prepared by the standard technique of grinding and polishing, followed by etching in a saturated solution of picric acid.In order to check out whether the mechanical properties of the as-cast Mg-RE alloy were improved by using the processing method proposed by the current study, a tensile test was also conducted. The dimension of the specimen is shown in Fig.1.

\section{Results and Discussion}

Corrosion properties. Mg-RE alloy expressed the qua morph as character which achieved the expected structure target at beginning, i.e., qua morphous pursed and fine crystalline phase dualphase material. In order to evaluate the corros on ance of the Mg-RE alloy, corrosion tests were conducted. It was adopted as comparison. A1,0, w used AZ31 sheet material as one more group of comparison.

The SEM image of the AZ31 Li t she after im crsed in $3.5 \% \mathrm{NaCl}$ solution for $48 \mathrm{~h}$ at $50^{\circ} \mathrm{C}$. As shown in Fig.2(a), some parto or were corroded seriously and dissolved into the corrosion solution. Fig.2(b) nows th trosion status of the other regions. The loose and cracked corrosion products gener and verm ar expanded as immersion time gets longer. It shows filiform corrosion.
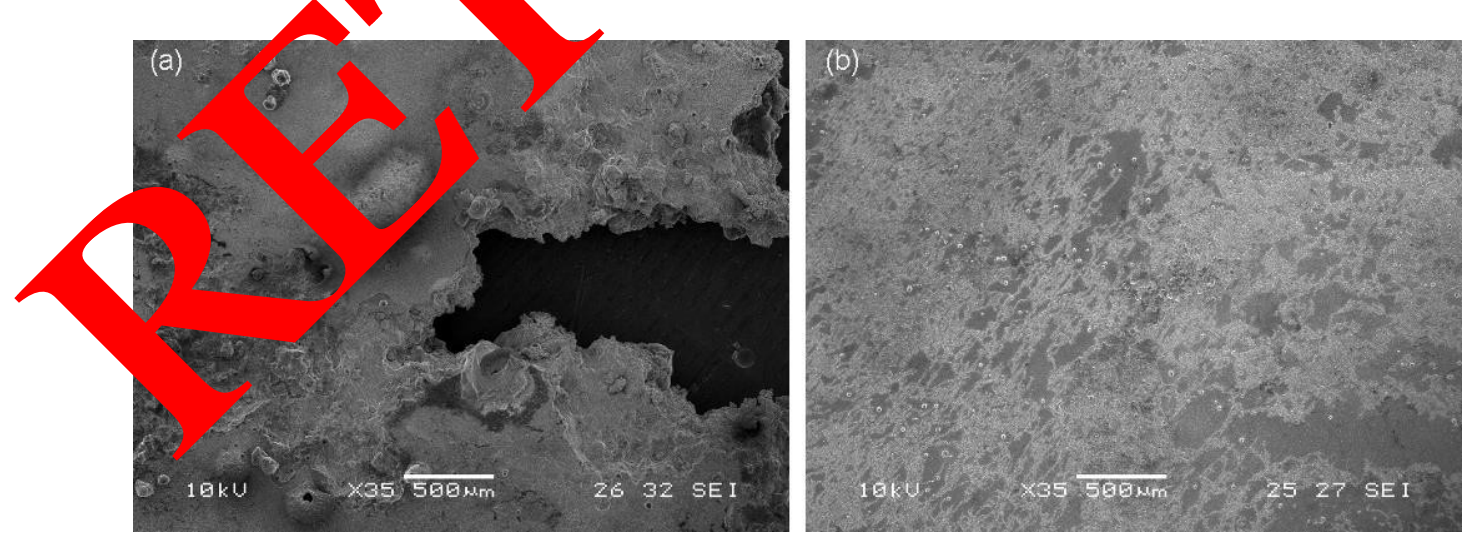

Fig.2. SEM image of the AZ31 sheet after immersed in $3.5 \% \mathrm{NaCl}$ solution for $48 \mathrm{~h}$ at $50^{\circ} \mathrm{C}$. 
As shown in Fig.3(a), it shows the results of SEM image of the corrosion products (left) and distribution map of magnesium on the corroded surface after corrosion (right). It can be found that the content of $\mathrm{Mg}$ decreased with the generation of corrosion products. This also reflects that the corrosion layer contains less amount of $\mathrm{Mg}$. Optical microscopy image in the cross-section of the corroded specimen was shown in Fig.3(b). It shows that the corrosion layer has a thickness of $10 \sim 20 \mu \mathrm{m}$.

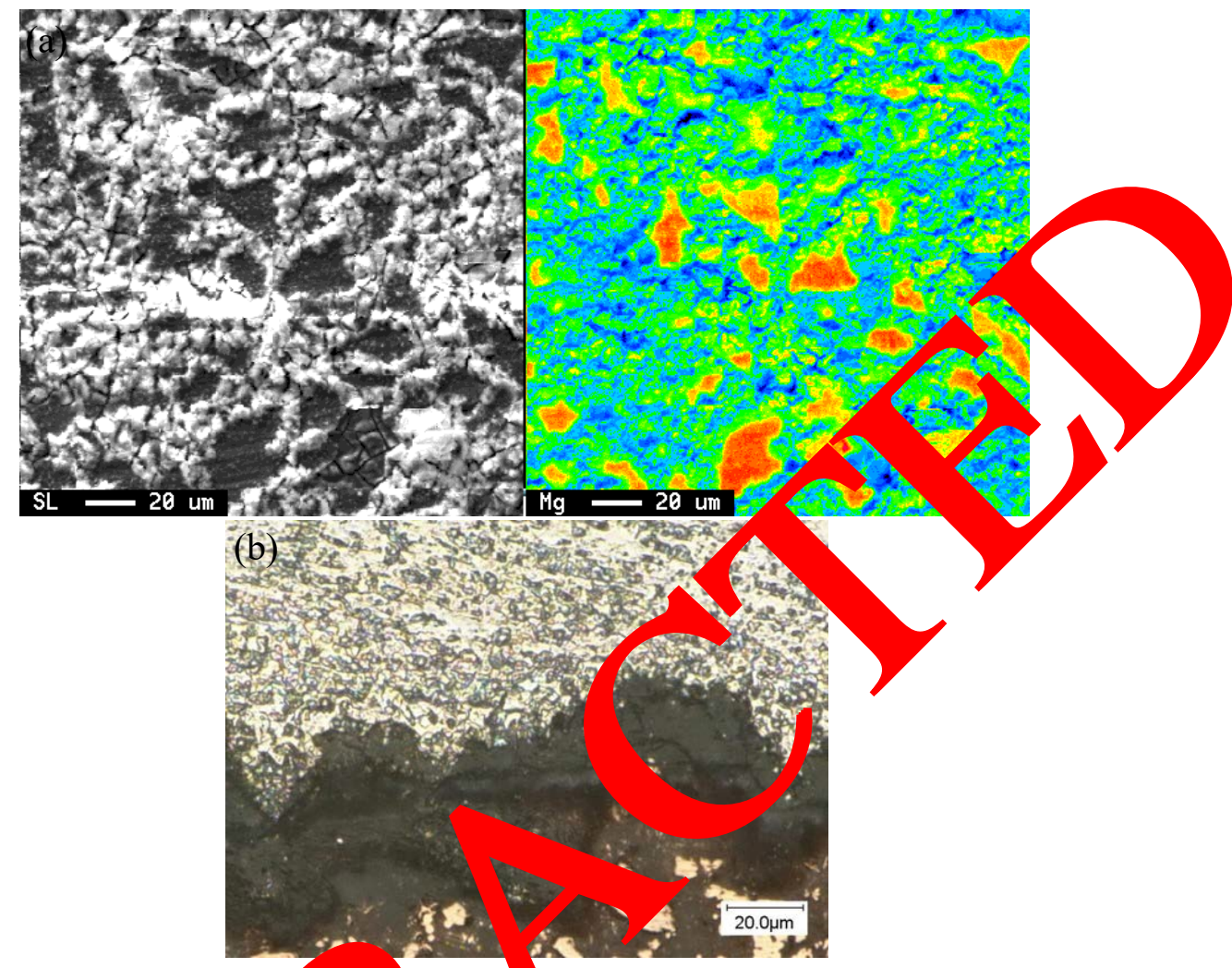

Fig.3. (a) Surface corrosion state and Ig ele nt distrit ton after immersion-AZ31 sheet. (b) Depth of the

Mg-RE alloy shows the be corros resistance among the current two alloys. As shown in Fig.4, the grain boundaries can identific Yearly after immersed in $3.5 \% \mathrm{NaCl}$ solution for $48 \mathrm{~h}$ at $50^{\circ} \mathrm{C}$ and only a very all a generated at the bao areas s vn in Fig.4(a) and make the sample surface appears local transgranular fra ture. ${ }^{\circ}$. 4(b) sh ws the SEM image in transverse section of the Mg-RE alloy specimen. The a sio frim too thin to be detected.

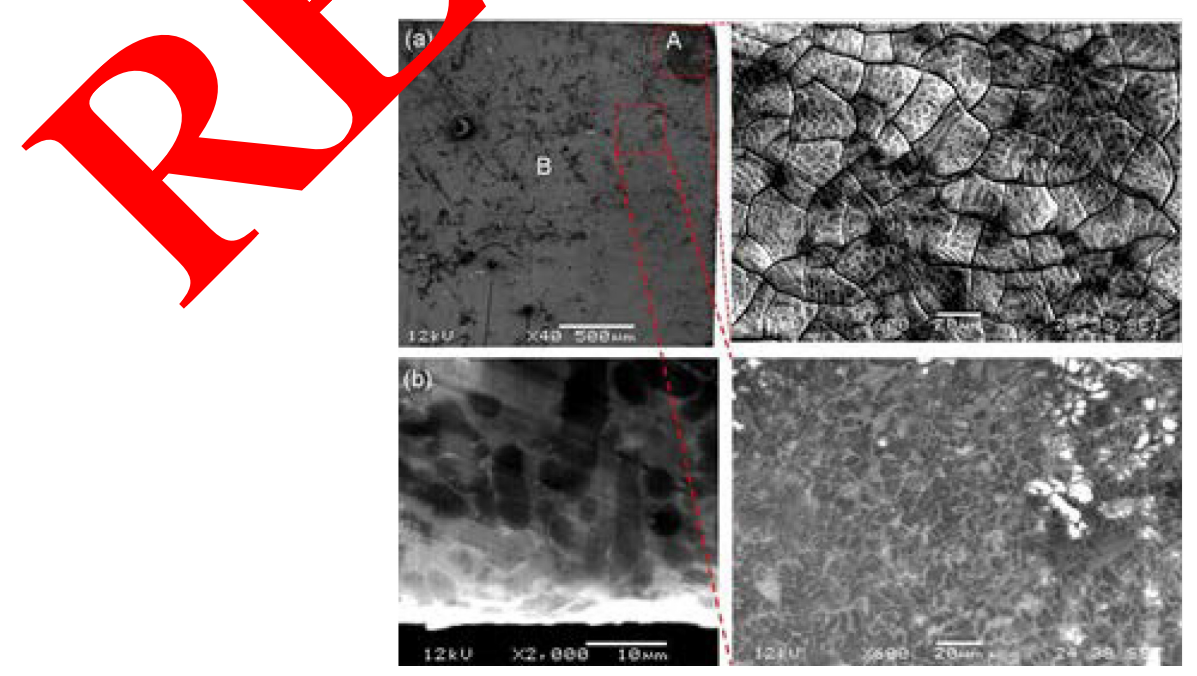

Fig.4. SEM image of the Mg-RE alloy sheet after corrosion: (a) surface; (b) transverse section. 
In order to evaluate the depth of the tiny cracks, the specimen was processed by FIB tool. SEM images of the prepared specimen were shown in Fig.5(a). We can see that the tiny cracks generated after immersion have a depth of less than $1 \mu \mathrm{m}$. As shown in Fig.5(b), the SEM image of the Mg-RE surface (left) and element mapping of magnesium after immersion (right) were analyzed. We can find that magnesium content decreased in the surface with cracks.

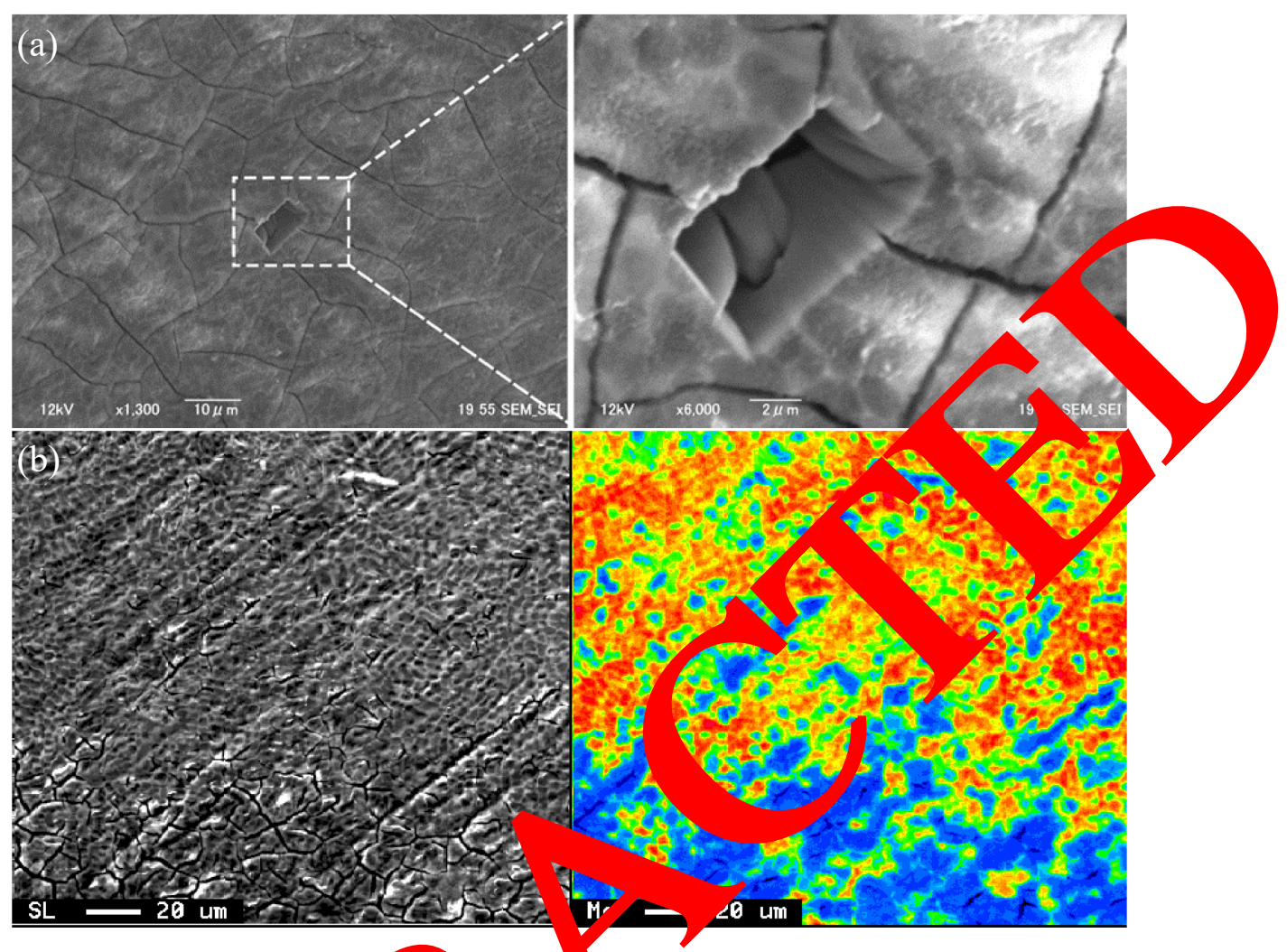

Fig. 5. (a) Tiny crack depth of the cor layer. (b SEM image and surface magnesium distribution of e Mg-E sample cer immersion.

Mechanical properties of th Camal p V MIg-KE alloy. Microstructure of the specimen surface and SEM image of the tensile ure surfac shown in Fig.6. In some place of the fracture surface, it showed a dimpled $\mathrm{p}$ tern, hich imp,es a ductile fracture feature, the size of dimples varied slightly. Most of pla ceveals ch age facets, which implies a brittle fracture feature.

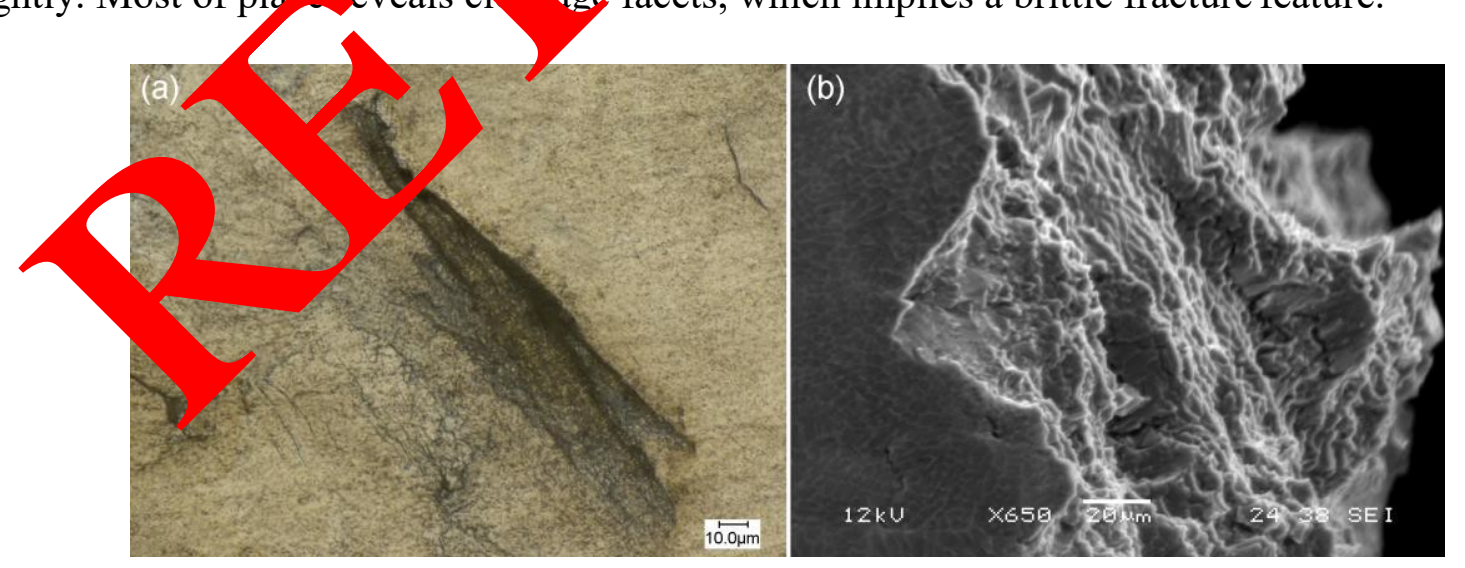

Fig.6. Surface microstructures (a) and tensile fracture (b) of the specimen after tension test.

Table 2. listed the ultimate tensile strength (UTS) of AZ31 as-cast strips at different casting conditions and the corresponding strips under different heat treatment. These AZ31 alloy strips were produced by the seniors in our laboratory. We list the average data of these as-cast AZ31 strips here in order to compare these average data with the Mg-RE alloy strip produced by rapid solidification process. 
Through the comparison, it is found that the elongation of Mg-RE alloy strip is high than the AZ91 and ZK61 under powder metallurgy processing and the ductility of the Mg-RE alloy made by rapid solidification TRC process was improve.

Table 2. Comparison of mechanical properties of AZ31 homogenized 1h strips with Mg-RE alloy made by rapid solidification TRC process.

\begin{tabular}{|c|c|c|c|c|c|c|c|}
\hline Materials & $\begin{array}{l}\text { Casting } \\
\text { speed } \\
(\mathrm{m} / \mathrm{min})\end{array}$ & $\begin{array}{l}\text { Pouring } \\
\text { temp. } \\
(\mathrm{K})\end{array}$ & $\begin{array}{c}\text { Strip } \\
\text { Thickness } \\
(\mathrm{mm})\end{array}$ & $\begin{array}{c}\text { Homogenization } \\
\text { temperature } \\
(\mathrm{K})\end{array}$ & $\begin{array}{l}\text { UTS } \\
(\mathrm{MPa})\end{array}$ & $\begin{array}{c}\text { Elongation } \\
(\%)\end{array}$ & Ref. \\
\hline AZ31 & 8 & 973 & & 673 & 183.7 & 9.25 & \\
\hline AZ31 & 13 & 953 & & 673 & 181.4 & 9.32 & \\
\hline AZ31 & 18 & 953 & & 673 & 225 & & \\
\hline AZ31 & 30 & 973 & & $673,2 \mathrm{~h}$ & 82 & & \\
\hline Mg-RE & 30 & 953 & 1.1 & As-cast & 215.88 & & \\
\hline $\begin{array}{l}\text { AZ91 Powder } \\
\text { metallurgy }\end{array}$ & - & - & - & - & & & \\
\hline $\begin{array}{l}\text { ZK61 Powder } \\
\text { metallurgy }\end{array}$ & - & - & - & - & & & \\
\hline
\end{tabular}

Rapid solidification of TRC experiments were conduct a. Mg-R. ${ }^{1} \mathrm{~g}_{\mathrm{y}}$ strip with the quasiamorphous phased and fine crystalline phase dual-pha e exhibited good corrosion resistance and higher ultimate tensile strength and elongation comp ing to the s-cast AZ31 alloy strips. The elongation of $\mathrm{Mg}-\mathrm{RE}$ alloy strip is also high than the 891 and $/ \mathrm{K} 61$ under powder metallurgy processing. These indicate that Mg-RE alloy praduced by dod has a better ductility.

\section{Acknowledgement}

This work was supported by Cooper in esearch nd Development Center for Advanced Materials (CRDAM) funded by the Instit for Materials Research (IMR), Tohoku University (Project Number 18G0042).

\section{References}

[1] $\mathrm{Xu} \mathrm{W}$, Birbilis $\mathrm{N}$ ha $\mathrm{G}$, al. A high-specific-strength and corrosion-resistant magnesium alloy [J]. Naty e materials, 2 14(12): 1229-12

[2] Davies H Yhap - Metallic glass formation [M]/LUBORSKY F E. Amorphous Metallic Alloys. Butter th-Hei cmann. 1983: 8-25.

[3] Wy G, an K- hu L, et al. Dual-phase nanostructuring as a route to high-strength nesi malloys dJ]. Nature, 2017, 545(7652): 80-83.

[4] Liang Cowley C B. The twin-roll strip casting of magnesium [J]. JOM, 2004, 56(5):26-28.

[5] Park S S, h Y S, Kang D H, et al. Microstructural evolution in twin-roll strip cast Mg-ZnMn-Al álloy [J]. Materials Science and Engineering: A, 2007, 449-451(Supplement C): 352355.

[6] Ding P-d, Pan F-s, Jiang B, et al. Twin-roll strip casting of magnesium alloys in China [J]. Transactions of Nonferrous Metals Society of China, 2008, 18(Supplement 1): s7-s11.

[7] $\mathrm{Hu} X-d, J u$ D-y, Zhao H-y. Thermal flow simulation of twin-roll casting magnesium alloy [J]. J Shanghai Jiaotong Univ (Sci), 2012, 17(4): 479-483.

[8] Kubota K, Mabuchi M, Higashi K. Processing and mechanical properties of fine-grained magnesium alloys [J]. Journal of Materials Science, 1999, 34(10): 2255-2262 